\title{
Os caminhos inexatos da ciência
}

\author{
The inexact routes of science
}

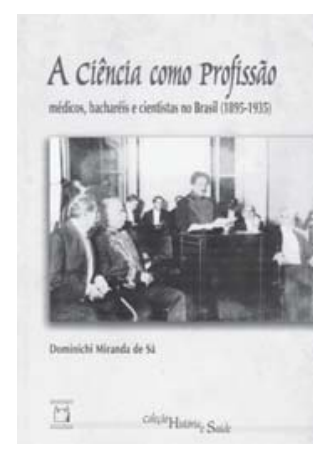

Sá, Dominichi Miranda de.

A ciência como profissão: médicos, bacharéis e cientistas no Brasil (1895-1935). Rio de Janeiro: Fiocruz, 2006. 216p. (Coleção História e Saúde).

\author{
Letícia Borges Nedel \\ Centro de Pesquisa e Documentação de \\ História Contemporânea do Brasil/Fundação Getulio Vargas/RJ \\ leticia.nedel@fgv.br
}

$\mathrm{P}$ oucos estudiosos da formação do campo intelectual brasileiro ousariam, hoje, desconsiderar a importância de agremiações de eruditos, institutos de pesquisa, museus, arquivos e bibliotecas criados ao longo do século XIX para a gestação das ciências e da comunidade acadêmica contemporâneas. Contudo, as características dos espaços onde se desenvolveram essas atividades, as formas privilegiadas de auto-representação pelos praticantes, as modalidades de acesso, enfim, os parâmetros conceituais e de sociabilidade que estruturaram hierarquias de autoridade entre agentes e disciplinas integrantes do particular ambiente acadêmico que antecedeu a implantação de um sistema educacional em nível superior no país, esses permaneceram por décadas temas alheios aos campos de experimentação freqüentados pela pesquisa de extração universitária. Enquanto nos estudos alinhados à história das ciências de viés naturalista reinou, por anos, o pressuposto de que experimentação e controle em laboratório fossem ingredientes necessários à titularidade científica, nas ciências sociais, em que essa condição é, por motivos óbvios, reivindicada com maior parcimônia, o paradigma institucional modelado por Max Weber não deixou de cumprir uma função pacificadora. Em tal domínio, embora os marcos fundacionais variassem entre o estabelecimento das universidades na década de 1930 e sua departamentalização ao final dos anos 1960, os balanços históricos tiveram o foco centrado em dois estados - Rio de Janeiro e São Paulo - e em duas perspectivas: uma, questionando os pressupostos dos estudos dos autores nacionais à luz do padrão e da qualidade da pesquisa desenvolvida em outros países; outra, aferindo os graus de 'autonomia científica' perante as opiniões e instâncias de decisão política. Por trás da convicção apriorista de que não era possível falar em especialidades e especialistas até que se estabilizassem as condições de produção de pesquisa 'isenta', a segunda geração de autores pós-graduados não deixou de farejar as dificuldades de lidar com essa 'história partilhada' (Corrêa, 1995, p.29). A começar pelo estatuto ambíguo dos registros, que não se reduziam à condição de fonte documental - suporte de informação - mas se constituíam também em veículo de memória pessoal para os interessados.

Dadas as complicações intrínsecas à proximidade com o objeto e considerando, além disso, a até agora débil interlocução entre as duas linhas de pesquisa aqui referidas - história das ciências e do pensamento social brasileiro -, não admira a quantidade de lacunas a suprir sobre o desenvolvimento de saberes formais, sobretudo em regimes de 
produção pautados pela ausência de um sistema unificado de títulos, regulador dos níveis de competência. Nesse aspecto, a obra $A$ ciência como profissão: médicos, bacharéis e cientistas no Brasil (1895-1935), escrita por Dominichi Miranda de Sá, chega aos pesquisadores curiosos de suas genealogias como um novo alento. Não pela veleidade de dar respostas definitivas a questões tornadas recorrentes, mas por redimensioná-las em sua historicidade, adotando uma perspectiva de estranhamento em relação ao objeto e à maneira como tem sido tratado.

Já nas páginas iniciais do trabalho, Sá declara aliar-se às revisões da história da atividade científica no Brasil propostas por Dantes, Figuerôa, Lopes e outros autores. No ato, toma a durável indiferença para com os movimentos culturais anteriores à Revolução de 1930 como um indicador da prevalência dos paradigmas 'universitário' e 'da importação cultural' sobre a historiografia produzida entre as décadas de 1970 e 1980. Argumenta que trabalhos de ampla circulação no período, como o de Schwarz (1977), Schwartzman (1979) e Miceli (1989, $1995,1979)$ reforçaram de maneira mais interessada do que interessante a idéia de uma descontinuidade radical entre 'a' ciência que praticavam nas universidades e as práticas 'pré-científicas' dos antecessores. A crítica endereçada àqueles estudos não se restringe, contudo, a mostrar que cederam subliminarmente aos apelos afetivos do objeto. Estende-se a seus referenciais de análise, baseados em juízos inaugurados quase um século antes, exatamente no bojo das lutas que acompanharam o surgimento do profissional da pesquisa aplicada em fins do século XIX e início do XX.

De fato, ao relativizar as espécies de 'ciência' e 'cientistas' passíveis de estudo, a investigadora trouxe à luz os aspectos mais estruturais das classificações disciplinares. Pôde explorar, dessa forma, as fontes de legitimidade, as disputas, as afinidades e os constrangimentos em jogo nas ocasiões em que os primeiros auto-reivindicados 'especialistas' trataram de definir e, principalmente, instaurar (já que a aclamação dos pioneiros é manobra fundacional obrigatória) os juízos que os distanciavam de 'amadores', 'retóricos', 'enciclopédicos' e 'generalistas'. A investigação mais desarmada dos cânones científicos confirma a hipótese, enunciada na abertura do livro, de que a "institucionalização universitária deveria ser interpretada como o remate do processo de especialização dos saberes e da individualização crescente das disciplinas, e não como o seu nascimento" (p.16). Essa problemática compôs a tese doutoral defendida junto ao Programa de Pós-graduação em História Social da Universidade Federal do Rio de Janeiro, em 2003, da qual o livro é uma versão revisada. Como o próprio título indica, enfocam-se ali as transformações impressas nos critérios de reconhecimento operados entre as elites culturais sediadas na capital federal do país, nas primeiras três décadas do regime republicano. Dividida em sete capítulos, a análise recupera as tensões que cercaram a emergência, no interior daquelas elites, de uma nova categoria profissional - a do 'cientista', defensor ingente da especialização intelectual e enunciador do que no título do capítulo VI aparece jocosamente descrito como a "Crítica da razão pomposa". 
O trocadilho sintetiza bem a pauta do debate intelectual delineada ao final do século XIX, a qual se estenderia como uma linha de fuga sobre as interpretações do Brasil elaboradas ao longo do século seguinte. Naquele contexto de intensas transformações políticas e sociais, críticos da ordem imperial recentemente desfeita, sintonizados com os pares de além-mar, lutam para impor a 'ciência' como o princípio ordenador da sociedade, chave explicativa da cultura, condição de acesso à civilização e via inescapável do progresso nacional. Polemistas do talante de um Sílvio Romero fundam então os elementos mais recorrentes de nossa memória histórica: a conhecida associação entre origem ibérica, passado escravista, aversão ao trabalho, tendência ao mimetismo - juízos que, muito antes de Schwarz cunhar a expressão 'idéias fora do lugar', percorreram a escrita de Silvio Romero a Fernando Azevedo, passando por Manuel Bonfim, Sérgio Buarque de Holanda e Paulo Prado.

Nos capítulos III e IV, Sá interpreta os meios pelos quais os cientistas, espécie de reformadores sociais 'condenados à civilização', restringem a entrada de estranhos em um terreno de honorabilidade tanto mais devassável quanto indefinido permanecesse. Altissonantes, seus discursos atacam áreas tradicionais como o direito e a literatura, que passam a representar o ultrapassado ufanismo romântico do antigo regime. Ao refundarem as bases de legitimidade social dos saberes e as condutas de seus representantes, os enunciadores revolvem também o vocabulário relativo à produção do conhecimento. Não por acaso, as acusações vão em par com o deslizamento semântico da 'literatura' designação cada vez mais restrita à prosa de ficção e à poesia - e com a subalternidade crescente das 'humanidades' perante as ciências naturais (ou 'positivas', na acepção comteana), mediante a projeção dos significados desde então desairosos de expressões como 'erudição', 'retórica' e 'bacharelismo' sobre o domínio da 'prosa subjetiva'. Dessa forma, "a identidade do 'cientista' vai-se constituindo em oposição à imagem do 'literato'" (p.16), ao mesmo tempo que este passa a disputar com o exército de jornalistas ocasionais as prerrogativas da arte profissionalizada.

Essas inflexões são detectadas em estatutos, periódicos, atas e discursos de academias literárias e científicas, além de jornais e semanários de vasta circulação na capital federal. Pelas mesmas razões por que renuncia à exploração de fontes de natureza bibliográfica - opção justificada diante do sucesso da divulgação científica nos periódicos e da maior abrangência social e espacial destes últimos em comparação aos livros -, Sá abre mão de uma narrativa pautada pela biografia, pelas obras e pela trajetória profissional dos protagonistas. Por mais ricas e instigantes que fossem as antologias e carreiras de homens como Roquette Pinto, Juliano Moreira, Carlos Chagas e Miguel Ozório, entre outros, ela prefere acertadamente percorrer as instâncias de consagração por onde circularam, as discussões em que se envolveram, as posições assumidas e as contradições maldisfarçadas na convivência com os pares e os ímpares. A escolha permite destreza na demonstração da não-linearidade do processo de normatização da ciência. As contradições, marchas e contramarchas são empiricamente confirmadas 
pelo fato de, para lá das freqüentes imprecações mútuas sobre o "desmazelo escrito dos cientistas" e o "papagaísmo dos literatos" (p.130), ambos os tipos não apenas se freqüentarem na Academia Brasileira de Letras (ABL), mas também se sobreporem - e isso não era absolutamente uma exceção à regra - numa mesma pessoa, como é o caso do médico e escritor polivalente Afrânio Peixoto, defensor fiel da controvertida entrada de homens de muita ciência e poucas letras na ABL.

Ressalte-se nesse ponto outro mérito da pesquisadora: Sá, atenta à necessidade de um aproche etnográfico às condições em que atuavam seus pares remotos, em nenhum momento se esforça para tornar coerentes as contradições intrínsecas ao cenário transitório em que apresentavam seus "atos de fala" (p.185). Ao contrário, amarrando os laços entre uma história das ciências, dos conceitos e das representações (referenciada em Lepenies, Koselleck e Hartog, mas também nos estudos da história intelectual francesa, nomeadamente os de Sirinelli, Charle, Prochasson, além da história social da cultura proposta por Chartier), a autora assume a postura de escuta do léxico desses protagonistas mais desejosos do que especializados, ressaltando a todo momento o sentido indiciário das contradições por eles vividas e a capacidade performativa dos discursos. Com isso, logra tanto delinear o quadro semântico que sustenta os cânones intelectuais de uma época quanto verificar, por meio deles, as diferentes possibilidades de reconfiguração da 'ciência', entendida como um conjunto de práticas mundanas, situada numa escala de valores e necessariamente sujeita às intempéries do tempo e da política. Desse eficaz artifício metodológico decorre a desnecessidade de "uma data precisa a fixar um fim ou um novo começo, [uma] 'causa' indiscutível a estabelecer, fazer encadear e explicar", relativas às mudanças nos padrões de produção intelectual do país. "Contemporaneidade dos debates, na Europa e no Brasil, e justaposição da herança cultual com os então novos paradigmas científicos são os elementos a reter nessa história" (p.186).

Para encerrar, um rápido comentário não exatamente crítico, mas inconformado sobre essa obra inspiradora e inspirada. E a propósito, o estímulo extraído de A terceira cultura (1979), de Wolf Lepenies (assumido pela autora na seção introdutória e no capítulo VI do livro), fica evidente nos termos com que se descreve o declínio do exercício letrado nos moldes do iluminismo, simultaneamente no Brasil e alhures. Não obstante, essa referência é cercada por opções metodológicas próprias, algumas adequadas, outras nem tanto. Isso, parece-me, é o que justifica a atenção dispensada à Academia Nacional de Medicina e à Academia Brasileira de Ciências, ou mesmo à ABL, em detrimento do Instituto Histórico e Geográfico Brasileiro. A academia histórica, diferente das agremiações imediatamente identificadas aos pólos 'científico' e 'literário', faz pouco mais que uma aparição furtiva, quase ao final do livro. A passagem, bastante oportuna, resgata um dado esquecido: o de que a indiferença de gerações de pesquisadores do campo intelectual recaiu exatamente sobre os precursores da proposta de criação de uma 'Universidade Brasileira', proposta essa entendida como mecanismo institucional indispensável à superação do atraso educacional do país 
já em 1911, quando se apresentou no Instituto o projeto de ensino superior em ciências e letras, mais tarde concretizado sob a forma de uma fugaz e ainda praticamente desconhecida Escola de Altos Estudos.

Mas, não obstante a consistência com que Dominichi leva a termo sua empreitada, a competência com que expõe a recíproca entre os desdobramentos da linguagem e a montagem do contexto intelectual em tela, é aqui que a análise se afasta do referencial inspirador. Enquanto Lepenies (1996) estrutura em torno dos pólos 'ciência' e 'literatura' a emergência de uma 'terceira cultura' marcada pela oscilação permanente entre os extremos de padronização da linguagem e da imaginação criadora, Sá furta-se a comentar a dimensão estatutária de uma ciência vizinha - a história - que, tanto quanto a sociologia, mas a seu próprio modo, também se encontrava a meio caminho de um termo e outro. Curiosa dispensa para uma jovem autora que, com a coragem própria dos convictos, reivindica para seu texto a legitimidade da prova. E não por ingenuidade, ao contrário. Por estar ciente de que "nesses tempos de 'relativismo cognitivo' em que a retórica figura como pura autonomia da linguagem, fazer referência à 'prova' significa tomar partido na historiografia" (p.183).

\section{REFERÊNCIAS BIBLIOGRÁFICAS}

Corrêa, Mariza

1995

Lepenies, Wolf

1996

Miceli, Sergio

1979

Miceli, Sergio (Org.) 1995

Miceli, Sergio (Org.) 1989

Schwartzman, Simon 1979

Schwarz, Roberto 1977
A antropologia no Brasil (1960-1980). In: Miceli, Sergio (Org.).

História das ciências sociais no Brasil. São Paulo: Sumaré, 1995. v.2. p.25-106.

A terceira cultura.

São Paulo: Edusp.

Intelectuais e classe dirigente no Brasil (1920-1945).

São Paulo: Difel.

História das ciências sociais no Brasil. v.2.

São Paulo: Idesp.

História das ciências sociais no Brasil. v.1.

São Paulo: Idesp.

Formação da comunidade científica no Brasil.

São Paulo: Cia. Ed. Nacional.

Ao vencedor as batatas.

São Paulo: Duas Cidades.

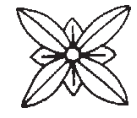

